\title{
Design of Nano Grid using Solar and Hydro System for Smart Homes
}

\author{
Shiwani Goyal ${ }^{1}$, Mrs. Shimi S.L ${ }^{2}$ \\ M.E. Scholar (Instrumentation and Control), NITTTR, Chandigarh ${ }^{1}$ \\ Assistant Professor, Electrical Engineering Department, NITTTR, Chandigarh ${ }^{2}$
}

\begin{abstract}
Smart homes are playing vital role in a smart grid, may no longer be modelled by passive load curves; because their interactive communication and bidirectional power flow within the smart grid affects demand, generation, and electricity rates. To consider such element natural properties, investigator utilize a multiagent-framework based approach in which singular homes are self-governing specialists settling on level headed choices to purchase, offer, or store power in view of their present and expected future measure of loading and capacity, representing the benefits each choice can offer. In the proposed plan, home operators prioritize their choices taking into account the expected utilities they give. Smart homes' expectation to minimize their power bills is in line with the framework. With an arrangement of contextual analyses and affectability investigations, investigator indicate how the general execution of the home agents joins as a new conduct to a harmony benefiting both the substances in various operational conditions and decides the circumstances in which routine homes would benefit from acquiring their own neighbourhood frameworks.
\end{abstract}

Keywords: Smart grid, Nano grid, MHTG-micro hydro-turbine generator, Smart Homes.

\section{INTRODUCTION}

In this study, investigator proposes and talk about brilliant homes that not just devour power but on the other hand are fit for producing also, putting away it utilizing their own energy and power capacity framework. Making it one stride further, investigator sees these homes as brilliant and flexible as they settle on self-ruling choices to deal with their power stockpiling. Moreover, they can connect with the grid to exchange power as it were that benefits them the most.In this project the investigator has also designed a hardware which is utilizing different energy inputs like solar, hydro etc. and converting it into standard voltage output in spite of the input fluctuations. This was a big challenge, however the results obtained are excellent and highly beneficial.

In remote and isolated areas, diesel generators are commonly used to provide electricity because grid connections are often neither available nor economically viable. Diesel generators are popular in remote area. The existing electrical power systems are experiencing a change from the traditional grid to the advanced grid named the Smart Grid. The new and advanced grid offers more flexibility and diesel generators are becoming expensive to run; they also need frequent maintenance. Most importantly, they pollute the environment. Hybrid power generation systems that combine different renewable energy sources and energy storage systems offer an environmentally friendly alternative for standalone operations [1]. A remote village in India, Salojipally, was selected for electrification using Solar Photovoltaic, Solar Thermal and Bio-Energy sources. In all, a $7 \mathrm{KW} \mathrm{PV} \mathrm{array} \mathrm{operated} \mathrm{water} \mathrm{pumps} \mathrm{for} \mathrm{irrigation,} \mathrm{fluorescent} \mathrm{lamps} \mathrm{for}$ street lighting \& indoor lighting, table fans, a TV set and a Transistorized radio receiver set [2]. There are many issues about energy management for wind/photovoltaic hybrid power system in order to improve energy efficiency. A digital controller of street lamp lighting system based on the AVR MCU can be designed to obtain maximum efficiency with less maintenance [3]. The performance of $21 \mathrm{PV}$-powered low pressure sodium lighting systems on a multi-use pathway has been observed Specific areas for evaluation include the constant voltage and on/off PV charge controllers, flooded deep-cycle lead-antimony and valve regulated lead-acid (VRLA) gel batteries, low pressure sodium ballasts and lights and vandal resistant PV modules [4]. A simple controller for street lighting application using an energy shaping method (Passivity-Based Control (PBC) can also be used [5]. The optimal design of photovoltaic hybrid system is time consuming and complex After characterizing the problem, an optimization method is selected because it seems that stochastic methods are the best at solving the problem [6]. The most notable feature of modern street lighting is the large number of electric lamps fitted with reflectors or glassware designed specially for distributing the total light most efficiently. the high candle-power arc lamps which electrical engineers had at their disposal for competitive purposes gave their maximum candle-power at an angle requiring that they should be placed at a considerable height, and at a short distance apart when required to obtain an even illumination [7].Similar, study is done on street lighting of Manchester. The detailed information relates to the lighting of Portland street Manchester, by means of flame arc lamps and the scheme adopted can only be judged by comparisons, data relating to earlier systems 


\section{IJIREEICE \\ International Journal of Innovative Research in Electrical, Electronics, Instrumentation and Control Engineering \\ ISO 3297:2007 Certified \\ Vol. 5, Issue 5, May 2017}

of arc lighting and contemporary systems of high-pressure gas lighting [8]. The existing electrical power systems are experiencing a change from the traditional grid to advanced grid named smart grid. The new and advanced grid offers more flexibility and stability to customers as well as for the producers of electrical energy. Smart Grid allows real time tracking and management of energy supply and demand thereby making the customer one of the essential roles in the whole power distribution system. To effectively deploy the Smart Grid and open widespread markets in wholesale and retail trading we need to develop stable market mechanisms and regulative that can be enforced. However, modeling markets may be a challenging task since there are numerous parameters and cases that need to be covered by simulations in order to produce reasonable and useful results.

The investigator is interested to work on the issue of simulating power market, and focuses in the tariff market (also known as the retail market). The idea behind the work is to create an intelligent trading agent that acts as a mediator between the end customers and producers by buying and selling energy. The ultimate goal of the agent is of course to acquire profit, but in order to do that numerous mechanism and logic have to be implemented. This study focuses on creating effective mechanisms and activities that are carried out throughout simulations. The most important part is the design and calculation of tariff system that are offered in the tariff market to customers. For any building, what will be the total expenditure in creating nano grid power generation, and what will be money back period, these are very important fact which must be calculated so that its feasibility may be checked.

\section{SMART GRID CONCEPT}

Traditionally, the term grid when used in the domain of electricity systems encompasses the meaning of all or at least one of the following actions:

i) Generation of electrical energy,

ii) Transmission of electrical energy,

iii) Distribution of electrical energy and

iv) Electricity control.

The concept of the Smart Grid (SG), also called smart power grid, smart electrical grid, intelligrid, intragrid, intergrid, intelligent grid or future grid is no different from the traditional term but with certain enhancements that contain the integration of information systems into the electrical energy distribution grid.

\section{PROPOSED WORK}

A case study has been done on M block of Pramukh Garden, a 12 storied building in Silvassa, Dadar and Nagar Haveli. Total energy consumed per annum is 2, 01,350.28. The hybrid solar and hydro system designed can be installed in the building and thereby energy produced with money back period can be calculated. Total energy developed per year from the hydro and solar setup is $2,04,301.25 \mathrm{KWH}$

\section{HARDWARE DEVELOPED}

A prototype of the hybrid system has been developed and tested in laboratory. The hardware consists of motorgenerator set, controller, solar panel and inverter.Th.e working model of the hybrid system is shown in Fig.1

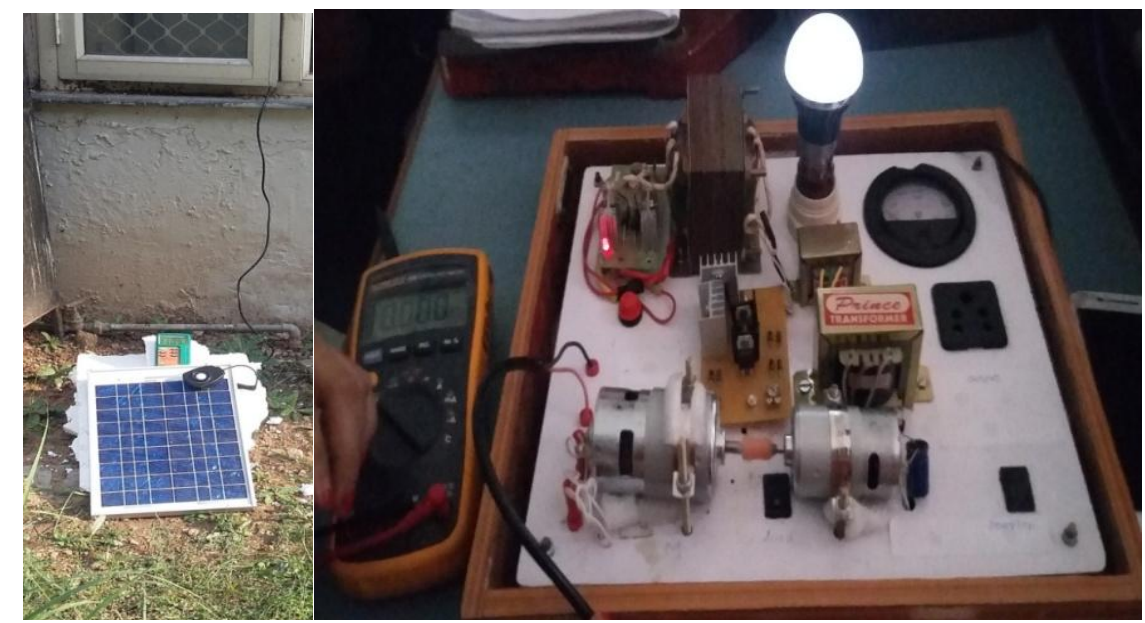

Fig. 1 Working Model of Hybrid System 


\section{International Journal of Innovative Research in} Electrical, Electronics, Instrumentation and Control Engineering

ISO 3297:2007 Certified

Vol. 5, Issue 5, May 2017

Table 15 Observation Table for Hybrid System (On Load Condition)

\begin{tabular}{|c|c|c|c|c|}
\hline S.No. & PV o/p (V) & Hydro o/p (V) & $\begin{array}{c}\text { Practical Value of AC } \\
\mathbf{o} / \mathbf{p}(\mathbf{V})\end{array}$ & $\begin{array}{c}\text { Theortical Value of AC } \\
\mathbf{o} / \mathbf{p}(\mathbf{V})\end{array}$ \\
\hline 1 & 4.41 & 8.11 & 20.13 & 28.41 \\
\hline 2 & 3.50 & 10.17 & 24.15 & 36.48 \\
\hline 3 & 6.01 & 7.99 & 26.58 & 39.05 \\
\hline 4 & 5.61 & 9.18 & 27.89 & 45.13 \\
\hline 5 & 5.72 & 9.16 & 31.23 & 49.68 \\
\hline
\end{tabular}

\section{RESULTS AND DISCUSSIONS}

The variation of practical value of output ac voltage from theoretical value is calculated in terms of error which is coming out to be $8 \%$. This has been observed that when the wattage of the hybrid system has increase the error has been reduced. Hence, efficiency of the system will be better. Thus, result obtained proves that system can be successfully implemented in real time on large scale.

\section{CONCLUSION}

There is severe power crisis in India. The main source of energy which is available everywhere is solar energy and water energy. Now a days the solar energy is used extensively everywhere. However this water energy at nano grid level is not utilized so efficiently. The investigator has given stress in the utilization of solar and hydro and reached to a conclusion that it is highly profitable and it can remove the shortage of energy problem upto some higher extent. The thesis report will be extremely useful for electrical and power engineers.

\section{REFERENCES}

[1] Haruni, A.M.O, "A Novel Operation and Control Strategy for a Standalone Hybrid Renewable Power System", IEEE Transactions on Renewable Energy and Power System, Australia, pp: 402-413, Volume: 4, Issue: 2, April, 2013.

[2] V. Ranjan, R. Agnihotri, S.K. Sangal and S.K. Shill, “Village Electrification - Salojipally Project”,IEEE Twentieth Photovoltaic Specialists Conference, Sahibabad India, pp:1211-1215, July, 1988

[3] Tao hen and Jin Ming Ang, "Research on Energy Management for Wind/PV Hybrid Power System", 3rd International Conference on Power Electronics Systems and Applications, China, pp: 1402-1406, September, 2009.

[4] Steve R. Harrington and Thomas D. Hund, "Photovoltaic Lighting System Performance", IEEE Twenty Fifth Photovoltaic Specialists Conference, Washington, pp:1307-1310, 13-17 May, 1996.

[5] Mohamed Becherif, Damien Paire and Abdellatif Miraout, "Energy Management of Solar Panel and Battery System with Passive Control", ICCEP '07, IEEE International Conference Clean Electrical Power, France, pp:14-19, March, 2007.

[6] Jeremy Lagorse, Stefan Giurgea, Damien Paire and Maurizio Cirrincione, "Optimal Design Analysis of a Stand-Alone Photovoltaic Hybrid System”, IEEE Industry Applications Society Annual Meeting, France, pp:1-7 , Jan, 2008.

[7] Haydn T. Harrison, "Street Lighting By Modern Electric Lamps", Electrical Engineers, Journal of the Institution, pp: 24-46, 24 ${ }^{\text {th }}$ Nov., 1911.

[8] S. L. Pearce, "Recent Developments In The Street Lighting Of Manchester", Electrical Engineers, Journal of the Institution, pp: 596-634, 6 March, 1913.

[9] Wang Yongqing, "Design of Solar LED Street Lamp Automatic Control Circuit”, IEEE International Conference on Energy and Environment Technology, China, pp: 90-93, august, 2009.

[10] Alekhya Datta, P, and M. Gujar "Accelerated Deployment of Smart Grid Technologies In India -Present Scenario, Challenges And Way Forward”, IEEE International Conference on IGST, New Delhi, Vol.92, pp: 1-5, 19-22 Feb, 2014.

[11] Preeti Bhatt, "Design and Cost Analysis of PV System Using Nano Solar Cell", International Journal of Scientific and Research Publications, Vol. 4, No. 3, March 2014.

[12] Rocky, T.H., "Nano Solar Grid (NSG): A Solution for Rural Market Power Crisis" IEEE International Conference on ICGET, Dhaka, Vol.2, pp. $14-17,5-6$ September, 2014. 